\title{
Computational Modelling of Cardiac Electrophysiological Changes in Malarial Fever
}

\author{
Laura Atkinson $^{1}$, Aneesha Basharat ${ }^{2}$, Alan P Benson ${ }^{2}$, Michael A Colman ${ }^{2}$, Arun V Holden², \\ George W Kagugube ${ }^{3}$, Eleftheria Pervolaraki ${ }^{2}$ \\ ${ }^{1}$ University of Newcastle, Newcastle, UK \\ ${ }^{2}$ Leeds, Leeds, UK \\ ${ }^{3}$ Busitima University, Mbale, Uganda
}

\begin{abstract}
Cardiac function is impaired in severe malarial fever, and ECGs show changes associated with repolarization. These could contribute to mortality via ventricular arrhythmia. The cardiac effects could be due to the malarial parasite load in the heart, specific cardio-toxic effects of the parasite or cardio-toxic effects of antimalarial agents.

We construct a simple 1-dimensional electrophysiological model for the physico-chemical changes clinically observed during malarial fever: with temperature, $\mathrm{pH}$ and [ionic] $]_{\text {plasma }}$ changes.

The model can quantitatively reproduce the tachycardia and $Q T_{c}$ prolongation seen in the adult, and shortening seen in the child during malarial fever.
\end{abstract}

\section{Introduction}

Malaria is a global grand challenge, with 214 million cases in 2015, resulting in over 438,000 deaths. $90 \%$ of these deaths are in were in sub-Saharan Africa, and 70\% in children less than 5 years old. Cardiac function, in terms of rate, stroke volume, ejection fraction and haemodynamic indices is impaired in severe malaria [1-3], and some antimalarial agents (the quinolines) affect ventricular repolarization, observed as QT interval prolongation [4,5].

In adults with malaria, fever bouts occur every few days, with temperatures up to $\mathrm{u}$ to $41^{\circ} \mathrm{C}$, associated with tachycardia and QT prolongation in the ECG [2] - see Figure 1. However, in children malarial fever is associated with QT shortening. This shortening is partly reversed by its treatment by quinolines- see Table 1 for representative values.

Longitudinal high resolution monitoring (multichannel ECG, ECGI) and imaging (CMR, echo) data sets of cardiac changes during malaria are largely lacking, as malaria is prevalent in countries with poorly developed health care systems. There is little experimental data on cardiac cell/tissue electrophysiology in animal models of malaria. This lack of data makes computational modelling premature. However, we aim to combine simple, readily available clinical measures with a simple cardiac electrophysiology model to quantitatively account for, and evaluate, cardiac ECG and mechanical changes during malaria. The objectives are to (a) construct a $1 \mathrm{D}$ computational model of normal sinus rhythm in the adult and child $<2$ years old, (b) incorporate known and putative changes in cell and tissue properties associated with malaria and to reproduce ECG RR, QT intervals during malaria in the adult and child, and (c) identify possible mechanisms for the differences in ECG during malarial fever seen in adults and children.

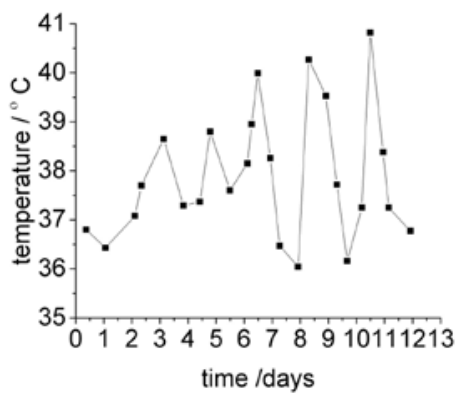

Figure 1. Example of temperature chart during a bout of malaria attacks: the cyclic oscillations result from the periodicity of the parasite life cycle in the RBCs

Table 1.Representative ECG interval/s data [4,5]

\begin{tabular}{rccc} 
& NSR & Mal & Mal+Quin \\
\hline Child RR & 0.57 & 0.42 & 0.49 \\
QT & 0.42 & 0.42 & 0.44 \\
Adult RR & 0.8 & 0.78 & - \\
QT & 0.39 & 0.25 & -
\end{tabular}




\section{Methods}

We are not aware of any cardiac cell/tissue electrophysiological data from patients with malarial fever, and so incorporate known physico-chemical effects of malaria from the clinical literature - elevated temperature, changed plasma ionic concentrations and acidosis (see Table 2) - into cardiac cell and tissue models, as the values for the extracellular fluid compartment.

Table 2, Clinical plasma parameter values [1,2]

\begin{tabular}{lcl} 
& Normal & Malaria \\
\hline $\mathrm{pH}$ & 7.4 & $<7.2$ \\
Temp & 37.5 & $>38$ \\
{$\left[\mathrm{Na}^{+}\right]$} & 140 & 120 \\
{$\left[\mathrm{~K}^{+}\right]$} & 5.4 & 3.9
\end{tabular}

Temperature appears explicitly in cardiac cell excitation models (as in RT/FZ) and implicitly via the $\mathrm{Q}_{10}$ for the voltage diffusion coefficient and the single and maximal channel conductances $\left(\mathrm{Q}_{10} \sim 1.2-1.5\right)$, for channel gating kinetics $\left(\mathrm{Q}_{10} \sim 2-4\right)$ and of exchange pumps $\left(\mathrm{Q}_{10} 3-3.5\right)$ and cross-bridge cycling transition rates $\left(\mathrm{Q}_{10} \sim 6\right)$. [6] The $\mathrm{Q}_{10}$ effect is to multiple the parameter by $\left(\mathrm{Q}_{10}\right)^{((\mathrm{T}-37) / 10)}$.

Extracellular concentrations are given in Table 2.The cell models are paced for 100 cycles. $1 \mathrm{~s}^{-1}$ to allow intracellular $\left[\mathrm{Na}^{+}\right]_{\mathrm{i}}$ and $\left[\mathrm{K}^{+}\right]_{\mathrm{i}}$ to approach steady values consistent with the initial values and membrane fluxes concentrations. Although there are models for intracellular $\mathrm{pH}$ dynamics, the electrophysiological changes due to acidosis are modelled simply by reduction in maximal $\mathrm{Na}^{+}$ and L-type $\mathrm{Ca}^{++}$conductances [7].

A 1D computational model for propagating activity during human normal sinus rhythm was constricted, with cell models based on the Courtemarche-Ramirez -Natel CRN atrial [8] and the O'Hara-Rudy [9] (with Na kinetics from CRN) families of ventricular cell models. Parameters for the sinoatrial and atrioventricular node cell models ( modified CRN models [10], were adjusted to give appropriate SAN rates for the age dependent RR intervals. The Purkinje fiber model was that of Stewart et al. [11]. Diffusion coefficients were selected to give atrial and ventricular conduction velocities of $0.42 \mathrm{~m} / \mathrm{s}$, and lengths (number of nodes) of the strand tissue components adjusted to reproduce PR and QT intervals of the ECG see Fig. 2

Propagation of $\mathrm{V}(\mathrm{t})$ in the 1-D strand was modelled by the non-linear partial differential equation:

$\partial V \partial t=\nabla(D \nabla V)-I_{\text {ion }} \partial \mathrm{V} \partial \mathrm{t}=\nabla(\mathrm{D} \nabla \mathrm{V})-\mathrm{I}_{\text {ion }}$

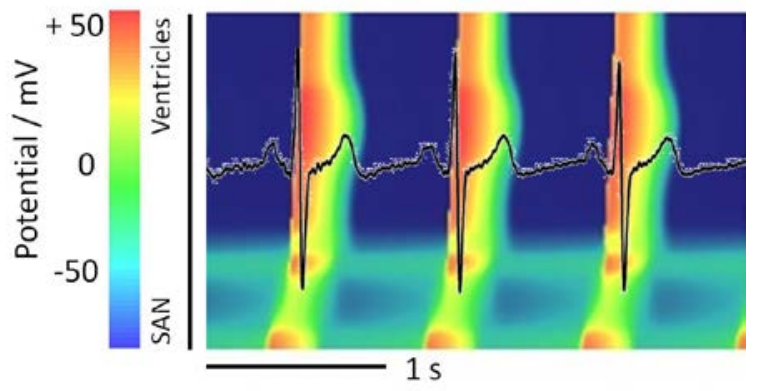

Figure 2: Adult NSR model. Space-time plot of numerical solutions of $1 \mathrm{D}$ strand model for normal sinus rhythm, with membrane potential colour-coded, superimposed on sample normal adult resting ECG.

Here, $V(\mathrm{mV})$ is membrane potential, $\nabla$ is a spatial gradient operator, and $t$ is time (ms). $D$ is the diffusion coefficient $\left(\mathrm{mm}^{2} \mathrm{~ms}^{-1}\right)$ that characterizes the electrotonic spread of voltage via local circuit currents, through cell-to-cell coupling by gap junctions, and the extracellular and intracellular resistances. $I_{\text {ion }}$ is the total membrane ionic current density $\left(\mu \mathrm{A} . \mu \mathrm{F}^{-1}\right)$. The parameters for $\mathrm{D}$ and for the equations for $\mathrm{I}_{\text {ion }}$ changed stepwise between the homogenous SAN, atrial, AVN, Purkinje and ventricular endo-, M- and epi-cardial tissues. Equation (1), with zeroflux boundary conditions, was solved numerically using a forward-time central-space scheme (with space steps of $\Delta x$ $=0.1 \mathrm{~mm}$ ) in conjunction with an operator splitting and adaptive time step method (to give time steps between $\Delta t$ $=0.01 \mathrm{~ms}$ and $\Delta t=0.05 \mathrm{~ms}$ ).

\section{Results}
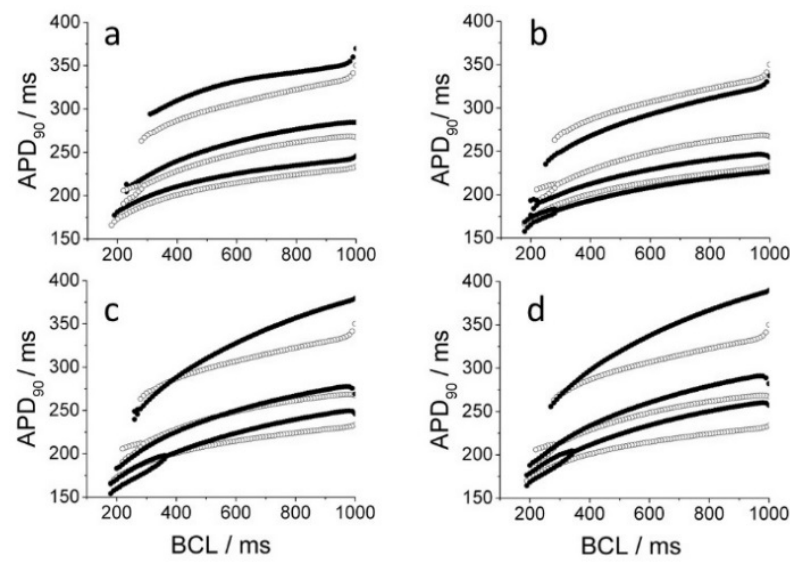

Figure 3. Computed ventricular $\mathrm{M}$-, epi- and endocardial APD 90 restitution curves , for (a) $[\mathrm{Na}]_{0}[\mathrm{~K}]_{0}$ changes (b) $\mathrm{pH}$ changes (c) temperature changes (d) all three physicochemical changes as a model for malarial fever. • with changed parameters with standard values for O'Hara Rudy [9] endo- (bottom trace) , M- (top trace) and epicardial (middle trace) cell models. 
Ventricular action potential duration (APD90) restitution curves for the endo-, $\mathrm{M}$ - and epi-cardial ventricular cell models ionic concentration, $\mathrm{pH}$ and temperature changes, and their combined effect in the electrophysiology cell model for malaria are shown in Fig.3 Fig.3a,b show the extracellular concentration changes applied in isolation prolong $\mathrm{APD}_{90}$, and the $\mathrm{pH}$ changes applied in isolation shorten $\mathrm{APD}_{90}$, at all rates, and for endo-, $\mathrm{M}$ - and epicardial cell models. However, the temperature increase applied in isolation (Fig. 3c) produces $\mathrm{APD}_{90}$ shortening at high rates and lengthening at lower rates (BCL $<540 \mathrm{~ms}$ for endo-; < 390ms for $\mathrm{M}$ cells). The $\mathrm{pH}$ and temperature changes also produce alternans at high rates.

When the $[\mathrm{Na}]_{\mathrm{o}}[\mathrm{K}]_{\mathrm{o}}, \mathrm{pH}$ and temperature changes are combined into a model for malarial fever (Fig 3d), there is $\mathrm{APD}_{90}$ shortening at high rates and lengthening at lower rates (BCL <300ms for epi-; < 320ms for M cells).
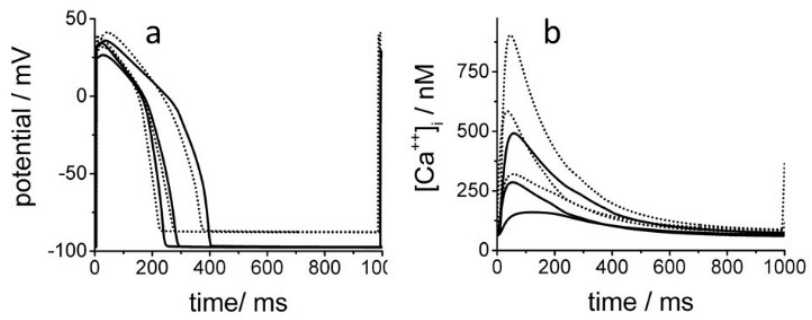

Figure4. Computed ventricular M-, epi- and endocardial (a) action potentials and (b) resultant $\left[\mathrm{Ca}^{++}\right]_{I}$ transients for malarial fever. Black solid lines: with changed parameters Dashed lines: with standard values for O’Hara Rudy endo-, M- and epi-cardial cell models . Periodic activity, paced at BCL of 1s.

The shortened $\mathrm{APD}_{90}$ in the malarial ventricular cell models (Fig4a) is associated with a reduced $\left[\mathrm{Ca}^{++}\right]_{\mathrm{I}}$ transient (Fig 4b), consistent with a reduced cardiac function.

The changes in physico-chemical parameters (temperature, explicit and implicit, via $\mathrm{Q}_{10} ; \mathrm{pH}$ and [ion] $]_{0}$ ) introduced to produce the "malarial" ventricular cell model are extended to all the tissue types in the strand, to produce an adult malarial NSR model (Fig. 5). The model for the child (a) has fewer nodes (b) the SAN node cell excitation parameters are modified by changes in the maximal $g_{f}$ and time independent $\mathrm{g}_{\mathrm{K} 1}$ conductances to produce the faster resting rate and (c) there were no changes in the parameters for the other tissues: the child model of Fig 6 is essentially a smaller adult model, with a higher rate.

The physico-chemical parameter changes that model malaria produce tachycardia in both the adult and child strand models, from a BCL of 820 to 517 in the adult, and from 610 to $480 \mathrm{~ms}$ in the child.. The QT intervals were computed from the peak of the $\mathrm{R}$ to the peak of the $\mathrm{T}$ wave in a pseudo-ECG from

$$
\Phi=a \int(-\nabla V)\left(\nabla\left(1 / x^{-} x^{\prime}\right)\right) \mathrm{d} x
$$

where $\Phi$ represents the unipolar potential recorded at an electrode $20 \mathrm{~mm}$ from the epi-cardial end of the strand, $a$ is a scaling factor, and $x-x^{\prime}$ is the distance from the electrode to any point in the tissue [11]. For both the adult and child models, the APD ${ }_{90}$ S and QT intervals in ms were shorter in the malarial model than the normal, whereas the $\mathrm{QT}_{\mathrm{c}}$ was prolonged in the adult (from 257 to $310 \mathrm{~ms}$ ) and shortened in the child (from 274 to $172 \mathrm{~ms}$ ).

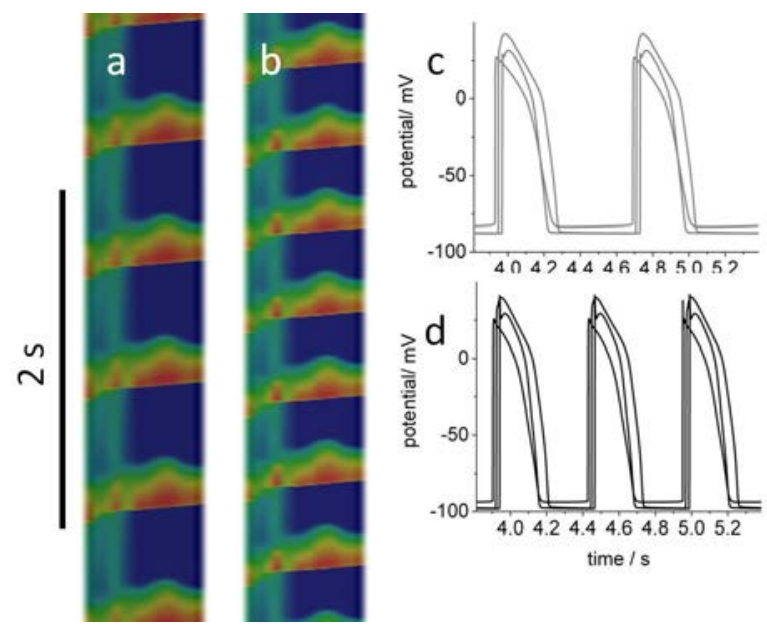

Figure5. Solutions for normal sinus rhythm for adult strand model showing malarial tachycardia. (a,b) Space-time plots and (c,d) propagating action potential solutions at second endocardial, mid-M cell and penultimate epicardial ventricular nodes. $(\mathrm{a}, \mathrm{c})$ standard model, with same parameters as in Fig.2; (b,d )
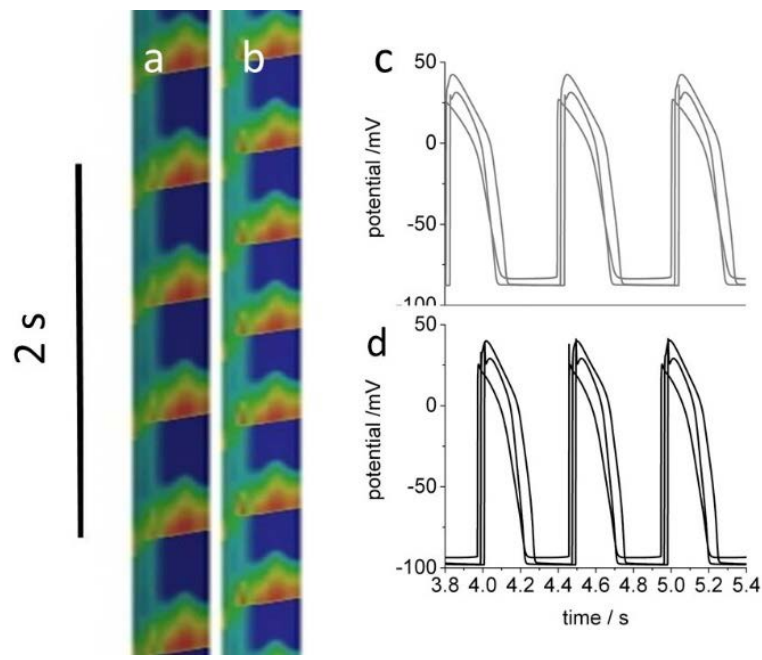

Figure 6. Solutions for child strand model, in same format as Fig5. 


\section{Discussion and conclusions}

There is a lack of quantitative i.e. digital recording during the initial fever and fever paroxysms, and so the data used in constructing the model, and the observations it reproduces, are very simple.

In the model, the major mechanism is that of temperature, and the key mechanism the different $\mathrm{Q}_{10}$ 's of the different ion transfer processes. Automated patch clamp experiments on the kinetics of human ion channel expressed in mammalian cell systems are widespread, but there is a lack of measurements of their $\mathrm{Q}_{10}$ 's through the clinical range of $35-41^{\circ} \mathrm{C}$. In this model we have taken the $\mathrm{Q}_{10}$ 's for diffusive processes, gated conductances, and pumps to be homogeneous: given the wide range in kinetics (sub ms - 100s of ms ) of cardiac membrane ionic currents it is likely that the Q 10 's vary considerably: the $\mathrm{Q}_{10}$ 's for channel gating kinetics in frog nerve at $22^{\circ} \mathrm{C}$ vary form 1.8-2.9 [13].

As such $\mathrm{Q}_{10}$ data becomes available it may be used to evaluate the relative roles of physical biophysical, and electrochemical factors in the ECG during malarial fever.

However, the simple models for the physical and electrochemical effects of malaria reproduce the principal ECG changes in malaria, without the need for postulating specific cardiotoxic effects. These specific effects (e.g. the parasite load interfering with the microcirculation) may occur, but are not necessary to account for the ECG changes that are observed during malarial fever.

\section{References}

[1] Yacoub S, Lang HJ, Shebbe M, Timbwa M, Ohuma E, Tulloh R, Maitland K. Cardiac function and hemodynamics in Kenyan children with severe malaria. Crit Care Med. 2010 Mar;38(3):940-5.

[2] Nguah SB, Feldt T, Hoffmann S, Pelletier D, Ansong D, Sylverken J, Mehrfar P, Herr J, Thiel C, Ehrhardt S, Burchard GD, Cramer JP. Cardiac function in Ghanaian children with severe malaria. Intensive Care Med. 2012 Dec;38(12):2032-41.

[3] Nayak KC, Meena SL, Gupta BK, Kumar S, Pareek V. Cardiovascular involvement in severe vivax and falciparum malaria. J Vector Borne Dis. 2013 Dec;50(4):285-91
[4] Touze JE, Heno P, Fourcade L, Deharo JC, Thomas G, Bohan S, Paule P, Riviere P, Kouassi E, Buguet A. The effects of antimalarial drugs on ventricular repolarization. Am J Trop Med Hyg. 2002 Jul;67(1):54-60.

[5] Roggelin L, Pelletier D, Hill JN, Feldt T, Hoffmann S, Ansong D, Sylverken J, Burhenne J, Fischer-Herr J, Mehrfar P, Thiel C, Burchard GD, Nguah SB, Cramer JP. Disease-associated QT-shortage versus quinine associated QT-prolongation: age dependent ECG-effects in Ghanaian children with severe malaria. Malar J. 2014 Jun 5;13:219.

[6] Tsien RW, Noble D. A transition state theory approach to the kinetics of conductance changes inexcitable membranes. J. Membrane Biol. 1969:1, 248-273.

[7] Shaw RM, Rudy Y. Electrophysiologic effects of acute myocardial ischemia: a theoretical study of altered cell excitability and action potential duration. Cardiovasc Res. 1997 Aug;35(2):256-72.

[8] Courtemanche M, Ramirez RJ, Nattel S (1998) Ionic mechanisms underlying human atrial action potential properties: insights from a mathematical model. Am $J$ Physiol 275:H301-21.

[9] O'Hara T, Virág L, Varró A, Rudy Y. Simulation of the undiseased human cardiac ventricular action potential: model formulation and experimental validation. PLoS Comput Biol. 2011 May;7(5):e1002061.

[10] Chandler NJ, Greener ID, Tellez JO, Inada S, Musa H, Molenaar P, Difrancesco D, Baruscotti M, Longhi R, Anderson RH, Billeter R, Sharma V, Sigg DC, Boyett MR, Dobrzynski H. Molecular architecture of the human sinus node: insights into the function of the cardiac pacemaker Circulation. 2009 Mar 31;119(12):1562-75.

[11] Stewart P, Aslanidi OV, Noble D, Noble PJ, Boyett MR, Zhang H. Mathematical models of the electrical action potential of Purkinje fibre cells. Philos Trans A Math Phys Eng Sci. 2009 Jun 13;367(1896):2225-55.

[12] Plonsey R, Barr RC (1988) Bioelectricity: a quantitative approach. Plenum, New York.

[13] Hille B. Ion channels of excitable ,membranes. (2001) Sinauer, Sunderland MA

Address for correspondence.

Arun V Holden

School of Biomedical Sciences

University pf Leeds

Leeds LS2 9JT UK.

a.v.holden@leeds.ac.uk 